\title{
PRACTICAL ASPECTS OF PERINATAL PSYCHOLOGICAL CARE
}

\section{Mosol N. O.}

\section{INTRODUCTION}

Current socioeconomic and demographic situation in Ukraine necessitates the implementation of effective actions and measures aimed at improving the health of the nation. Promoting the health of population and well-being of the future generations are very important goals. Improving of perinatal care is one of the priorities. System of perinatal care is aimed to protect the health of mothers during pregnancy, childbirth and postpartum period.

Perinatal care includes having access to a range of good-quality information and services: family-planning counseling, information, education, communication and services, including access to safe and effective contraceptive methods; education and services for prenatal care, safe delivery and post-natal care, infant and women's health care, parental education. Existing perinatal care should be improved by implementation effective service and evidence-based principles of care. In addition to effective perinatal care, the psychological care is a priority.

Psychological component of perinatal care includes a complex of measures aimed at providing psychological support to women and families at the stage of planning pregnancy, during pregnancy and postpartum period. Perinatal psychology is a a relatively new interdisciplinary science relating to person's earliest development, including conception, birth experience and early postnatal period. The important goal of perinatal psychology is to integrate the knowledge relating to pregnancy, birth, early development and therapy, and to promote its incorporation by relevant professions and recognition by the public.

The scientific research of perinatal issues is important and relevant:

- Perinatal mental health has become a significant public health concern; recent studies and Mental Health surveys in many countries indicate growing demand for psychological support during pregnancy and postpartum period ${ }^{1}$;

- The perinatal period is a unique developmental phase, where all family members need to be considered and supported;

- The implementation of effective perinatal care determines reduction of maternal and neonatal morbidity and mortality, thus the important goal of

\footnotetext{
${ }^{1}$ The British Psychological Society. URL: https://www.bps.org.uk/
} 
perinatal care system is to promote prenatal health and positive birth outcomes;

- Besides the effective perinatal care, psychologically sensitive, multidisciplinary, and culturally appropriate care is a priority;

- Infancy is a critical time for emotional and social development, and early parenthood is a psychologically vulnerable time for both mothers and fathers;

- Conscious parenting is fundamental to promote well-being and harmonious development of a child and it can be formed through special educational programs for (future) parents.

\section{Basic Principles of Perinatal Care: Psychological Component}

Recommendations from the World Health Organization (WHO) suggested that inappropriate perinatal care and technology continue to be practiced throughout the world, despite the acceptance of evidence-based principles and care. It has led to the identification of WHO principles of perinatal care ${ }^{2}$.

The WHO Principles of Perinatal Care are the following:

1. Care for normal pregnancy and birth should be demedicalized, meaning that essential care should be provided with the minimum set of interventions necessary and that less rather than more technology be applied whenever possible.

2. Care should be based on the use of appropriate technology, which is defined as a complex of actions that includes methods, procedures, techniques, equipment, and other tools, all applied to solve a specific problem. This principle is directed toward reducing the overuse of technology or the application of sophisticated or complex technology when simpler procedures may suffice or indeed be superior.

3. Care should be evidence-based, meaning supported by the best available research, and by randomized controlled trials where possible and appropriate.

4. Care should be regionalized and based on an efficient system of referral from primary care centers to tertiary levels of care.

5. Care should be multidisciplinary, involving contributions from health professionals such as midwives, obstetricians, neonatologists, nurses, childbirth and parenthood educators, and social scientists.

6. Care should be holistic, and should be concerned with intellectual, emotional, social, and cultural needs of women, their babies and families and not only with their biological care.

\footnotetext{
${ }^{2}$ Chalmers, B., Mangiaterra, V., \& Porter, R. (2001). WHO Principles of Perinatal Care: The Essential Antenatal, Perinatal, and Postpartum Care Course. Birth, 28(3), 202-207.
} 
7. Care should be family-centered and should be directed toward meeting the needs of not only the woman and her newborn but also of her partner and significant family or friends.

8. Care should be culturally appropriate and should consider and allow for cultural variations in meeting these expectations.

9. Care should involve women in decision-making.

10. Care should respect the privacy, dignity and confidentiality of women.

The WHO Principles of Perinatal Care were accepted and partially applied but have not been fully implemented. Disseminating the concepts and implementing them in practice are the current challenges. Besides the effective perinatal care, psychologically sensitive, multidisciplinary, and culturally appropriate care is a priority. The implementation of psychological component of perinatal care is provided through psychosocial care realized by perinatal psychology practice.

In 1971 Dr. Gustav Hans Graber initiated the foundation of the International Study Group for Prenatal Psychology (ISPP) in Vienna. Later it became the International Society of Prenatal and Perinatal Psychology and Medicine (ISPPM) ${ }^{3}$. The psychoneuroendocrinology of pregnancy and birth (P. Fedor-Freybergh) also proved to be the link between psychology and medicine. Thus obstetrician-gynecologists, neonatologists, pediatricians and endocrinologists approached the development of perinatal psychology.

Theoretical and methodological basis of perinatal psychology was founded by development of psychoanalysis (Z. Freud, A. Freud) and its directions: object relations theory (O. Rank, M. Klein, D. Winnicott), attachment theory (J. Bowlby), transpersonal psychology (S. Grof) and others. The multidisciplinary nature of perinatal psychology is defined by the involvement of different sciences. Integration of knowledge from many fields has never been more important. The significant contribution was made by obstetrician-gynecologists (F. Leboyer, F. Lamaze, G. Dick-Read, recent scientific findings of M. Odent ${ }^{4}$ ).

Development of perinatal psychology in Ukraine was impacted by psychology of parenthood and reproductive psychology of G. Filippova, perinatal psychotherapy of I. Dobryakov, theoretical grounding and practical aspects of perinatal psychology correction of $\mathrm{N}$. Kovalenko practice of preparation for parenthood.

Therefore, perinatal psychology is a new scientific field that emerged in conjunction of different sciences - medicine, neurobiology, psychology, anthropology, human ethology. The main work of the perinatal psychology scientific society is to research and to deepen understanding of development in the context of physiology, nutrition, epigenetic, endocrinology, psychology,

3 The International Society for Pre-and Perinatal Psychology and Medicine. URL: https://isppm.de/

${ }^{4}$ Odent M.(2013). Childbirth and the Future of Homo sapiens. Pinter \& Martin. London. 
pedagogy, cultural science, psychotherapy and application of this understanding in practical life.

The main task of perinatal psychology practice is psychological support of women and families during pregnancy, childbirth and postpartum period. The important goal of perinatal psychological support is to create the optimal conditions for the comprehensive development of a child (to promote intellectual, emotional and social potential of a child) through education and harmonization of family relationships ${ }^{5}$.

The practical goals of perinatal psychology include optimization and correction of mental health problems, improving reproductive health of parents and child development; preparation of couples for conception, pregnancy and childbirth; perinatal education; early prevention of psychological disorders.

More specifically the tasks can be defined as following:

- psychological support of pregnant woman and families that includes educational component and psychological correction;

- work with families expecting babies or planning pregnancy (special training programs, individual and group counseling);

- psychological assistance during childbirth (labor support);

- support of woman and families after birth (a wide spectrum: work with postpartum depression, breastfeeding support, counseling on issues of early development of a child).

The perinatal period is a unique developmental phase. Prenatal and early natal stages determine our biology and psychology make up to a great extent. As a result of research-based evidence the prenatal period was defined as a separate stage of personality ontogenesis ${ }^{6}$. Scientific studies have proved that prenatal development provides not only physical but also mental health of a child and such characteristics emotional and intellectual potential, action pattern when faced with difficulties and, to some extent, characteristics of our identity (D. Chamberlain ${ }^{7}$, S. Grof ${ }^{8}$, T. Verny ${ }^{9}$ ). The perinatal period is a developmental phase, where all family members need to be considered and supported.

${ }^{5}$ Guba N., Mosol N., Syusyuka V. Promoting Prenatal Health And Positive Birth Outcomes: Perinatal Psychological Support. Problem space of modern society: philosophical-communicative and pedagogical interpretations: collective monograph. Warsaw: BMT Erida Sp. z o.o. 2019 C. P. 166-180.

${ }^{6}$ Craig G., Baucum D. (2002) Human Development (9th Edition). Upper Saddle River, NJ : Prentice-Hall.

${ }^{7}$ Chamberlain D. (1998). The Mind of Your Newborn Baby. North Atlantic Books.

${ }^{8}$ Grof S. (1985) Beyond the Brain: Birth, Death and Transcendence in Psychotherapy. State University of New York Press.

${ }^{9}$ Verny Thomas R. (1981).The Secret Life of the Unborn Child, (with Kelly). Summit Books, USA and Collins, Canada. 
Practical aspects of perinatal psychological support comprise: comprehensive work with pregnant women / families, optimization of the content and development of the maternal sphere of the woman, work on the development of the "mother-(father)-child" system; psychological support at all stages: conception, pregnancy, childbirth, postpartum period.

\section{Practical Aspects and Methods of Perinatal Psychology}

The main directions of perinatal psychology practice are the following:

- Psychological diagnostic;

- Psychological prevention and education;

- Psychological correction and psychotherapy;

- Psychological counseling.

Psychological Diagnostic. Psychological assessment is very important for providing effective perinatal care. The specialized diagnostic tools can be used in work with pregnant and families. The psychological diagnostic can help psychologists, gynecologists, family physicians and psychotherapists to provide woman /family with timely, qualified psychological help.

For the purpose of psychological diagnostics, the following parameters are usually studied: personality assessment; psycho-emotional state of a pregnant woman; the type of pregnancy experience; identification of attitude towards the future child; identification of peculiarities of becoming a parent and the features of pregnancy experience; diagnostic of marital relations and satisfaction with the marriage.

\section{Personality Assessment Tools.}

Personality Questionnaire of Bekhterev Institute (PQBI). The questionnaire is intended for diagnostics the types of attitude to the disease and treatment. Its application is fundamental for the diagnosis of the role of psychosomatic component for women with extragenital pathology that is very common for pregnant.

Eysenck Personality Questionnaire $(E P Q)$. This is a three dimensional personality assessment tool: Extraversion-Introversion, Neuroticism-Stability, Psychoticism. Both of these dimensions (Extraversion and Neuroticism) are introduced as temperamental aspects of personality that are inherited and evident at birth. The two dimensions or axes, extroversion-introversion and emotional stability-instability. The questionnaire shows the connection between types of temperaments and the results of a factor-analytic description of personality.

Strelau Temperament Inventory (STI). It provides a measure of the basic central nervous system (CNS) properties (strength of excitation, strength of inhibition, and mobility of the CNS with a 4-point rating scale format. 
questionnaire allows us to assess the strength of excitation (SE), strength of inhibition (SI), mobility (MO), and balance (BA).

\section{Assessing Psycho-Emotional State.}

Taylor Manifest Anxiety Scale (TMAS). This test would be useful in the study of as a personality trait and anxiety disorders.

Test Anxiety Inventory (TAI). Spielbergers Test Anxiety Inventory is a selfreport instrument. It contains three subscales: Test Anxiety-Total (TAI-T), Test Anxiety-Worry (TAI-W), and Test Anxiety-Emotionality (TAI-E). This test is very informative for assessing psycho-emotional state of a pregnant woman.

Test of self-esteem evaluation of differential functional state (well-being, activity, mood). The test is intended for operative estimation of state of health, activity and mood.

Zung Self-Rating Depression Scale. It is a short self-administered survey to quantify the depressed status of a patient.

Identification of Attitude Towards the Future Child, Attitude to Pregnancy.

The Perceived Stress Scale (PSS). It is the most widely used psychological instrument for measuring the perception of stress. It is a measure of the degree to which situations in one's life are appraised as stressful.

Test of attitude to pregnancy by I. Dobryakov ${ }^{10}$. On the basis of the test of pregnant woman's relations developed by I.V. Dobryakov the author considers the subtypes of psychological component of gestational dominant (PCGD). On the basis of the study of anamnestic data, clinical and psychological observations of pregnant women and clinical conversations there were identified five types of psychological component of gestational dominant: optimal, euphoric, hypogestognostic, anxious and depressed).

Projective method "Me and my child" by G. Filippova". This pictorial method helps to define the style and maternal relation. The task of the method is to identify the features of pregnancy experience and the situation of motherhood, the perception of woman and her child, Interpretation is done according to the criteria adopted in psychodiagnostics for drawing tests.

Projective methods (drawings, writing "Parent essay").

Diagnostic of Marital Relations and Satisfaction with the Marriage.

Marital Satisfaction Questionnaire. The questionnaire is intended for express-diagnosis of the degree of satisfaction / dissatisfaction with the marriage, as well as the degree of consistency / inconsistency of marriage satisfaction in one or another social group.

\footnotetext{
${ }^{10}$ Dobryakov I.V. (2015). Perinatal psychology. Saint Petersburg: Piter [in Russian].

${ }^{11}$ Filippova, G.G. The method of drawing tests in psychological work with pregnant women. [Online] Available from: http://childpsy.ru/lib/articles/id/9574.php (Accessed: 20 December 2019).
} 
Role Expectations and Claims in Marriage. The test is aimed at clarifying the spouses' ideas about the importance of sexual relations in the family life, the personal unity of husband and wife, parental responsibilities, professional interests of each spouse, household services, moral and emotional support, external attractiveness of a partner.

Psychological Prevention and Parent Education. The National Institute of Child Health and Human Development ${ }^{12}$, which measured the impact of both child care and parents on children's development, concurs that parenting has the primary influence on children's development. Only a small number of parents report effective education and support. There are very few programs to prepare and educate new parents. Parents have the least knowledge about social and emotional development, the two areas in which parents believe they have the most influence. Parents seek parenting and child development information and support from family members, grandparents, friends, doctors, television, the Internet, books and magazines. The result is a patchwork of efforts that provide only superficial and sometimes fragmental information.

Qualified and effective educational work with future parents is an important goal of psychological perinatal support is. Parent education services and programs should be revised and developed. The most relevant topic for expectant parents is preparation for childbirth, but it is necessary to broaden the context of work and discuss the issues of parenthood: interaction with a child, the mother and father role in child development, family upbringing traditions. The effective perinatal support is provided by team work of specialists (neonatologist, psychologist, obstetrician-gynecologists).

The promotion of intellectual, emotional and social potential of a child is carried out trough parental education. Programs for future parents have different forms - individual or group work, parent clubs or courses of preparation for childbirth. The typicall program for future parents includes theoretical component (lectures, discussions, video, reading special materials) and practical work (art-therapy, training, relaxation), counseling of professionals (midwives, psychologists, pediatricians). The content of the training program varies but usually include: information on various aspects of pregnancy and childbirth, characteristics and dynamics of the emotional state of women and men, partnership in the family (not only partnership in labor, but in the wider context of parenting roles), issues of early child development and upbringing.

Another important task is popularization of perinatal knowledge and promotion of perinatal culture. Modern society is characterized by

\footnotetext{
${ }^{12}$ National Institute of Child Health and Human Development. URL: https://www.nichd.nih.gov
} 
dysfunctionality of major social institutions, devaluation of family values, deterioration of parent-child relationships. There is a major shift from traditional to alternative models of family and marital relations, increasing the marriage age and, therefore, the birth age. The number of children in the family is being decreased (it can be one child or child free families). We believe that perinatal education helps to raise a generation that is capable of conception, gestation and birth of a healthy child. Perinatal education contributes to positive attitude toward parenthood and birth of a child as a natural joyous event, provides knowledge regarding the physiology and psychology of pregnancy and childbirth. Perinatal education promotes forming of parental responsibility and parent's competence, conscious parenting.

The subjects of family education are parents, children, family, and community. Its main task is to raise physically, intellectually, spiritually and morally developed person. Formation of perinatal culture is an important outcome of perinatal education. Perinatal culture is a set of ideas and philosophical views of society, reflected in the existing customs and traditions on the processes of family planning, pregnancy, child birth and childhood. This issue relates to the culture of parenthood and family values and is very important in the context of future generation.

Preparing for future family life and formation of conscious parenting are very important tasks. Current socio-economic realities have changed traditional "motherhood" and "fatherhood" models. Promoting of conscious and responsible parenthood is an important goal of perinatal education that is practically realized through educational programs and training courses.

Educational component provides a significant psychological effect. However, information should be presented in an accessible and positive form covering relevant topics for parents. The effective learning is provided by means of interactive lectures, open discussions, role games, brain-storming, debates.

Responsible (or conscious) parenting is closely linked to such phenomena as paternity, parental love, willingness, responsibility, parental competence. Conscious parenting is fundamental to promote well-being and harmonious development of a child. Parenting is a lifelong journey as parents learn and apply new knowledge, acquiring the qualities and skills necessary for responsive parenting.

The analysis of international practices gives the possibility to apply the experience of effective programs. Developed in Australia Triple P-Positive Parenting Program emphasizes the prevention of problems and has the flexibility to move from simply providing information and advice to parents, to intensive family intervention if necessary. International research indicates that Triple $\mathrm{P}$ and the Incredible Years BASIC parent training program 
(for parents with children aged two to seven years) are particularly effective programs for parents of young children.

Issues of support and assistance of young families are one of the priorities of social policy. The Concept of Safe Maternity and Childhood is addressing the issues of ensuring favorable conditions for the health protection of women and newborns, promoting the role and place of the family in society and enhancing parental competence.

In Ukraine parental education and counseling is provided by state services such as Social Services for Family, Children and Youth, Centers for Reproductive Health and Family Planning, Schools of Conscious Paternity at the Antenatal clinics. Last decades many non-governmental organizations have started their programs (Associations of Conscious Parents, Communitybased Family Centers etc).

Work with expectant parents can be done individually or as a group work, each form has its own peculiarities and specifics. Group work is considered to be more effective. It provides peer support that gives additional therapeutic effect. This form of work also creates conditions for discussing relevant topics for future parents, gives an opportunity to meet with a variety of ideas and beliefs and to determine personal set of beliefs. The skills developed as a result of group work also help in resolving conflict situations in the family life, which has a harmonizing effect on marital relations. The task of the psychologist in this context is to facilitate the work of the group, to create a positive atmosphere and to develop the skills of tolerant behavior.

The important tasks of effective services for parents are: to provide reliable and relevant information for parents, to support the family, to enhance parental skills and responsible parenting, to promote establishing a good parent-child relationship.

Psychological Correction and Psychotherapy. Psycho-emotional state is an important component of human health, it's influences on the life and wellbeing of a person is extremely important and becomes of particular importance during pregnancy. Perinatal period is considered as a crisis stage, because it imposes special requirements on personal/family resources and carries both potential opportunities and potential threats.

Perinatal psychology has a comprehensive range of methods. Psychocorrectional work combines different form and methods of psychological work (art-therapy, body-oriented practices, meditation, relaxation).

Art-therapy is very effective form of psycho-correctional work. Techniques used in art-therapy include drawing, painting, sand therapy, game therapy, music therapy. With the help of pencils, paints or clay parents express their moods and anxieties, expectations, and fears. The variety of arttherapeutic techniques helps to gain experience of understanding and 
comprehending of feelings, forming the ability to be in contact with oneself and others. Art-therapy primarily aims to help individuals experiencing emotional and psychological challenges achieve personal well-being and improved levels of function.

Body-oriented practices (relaxation, breathing, special techniques) are very effective in harmonizing the psycho-emotional state. Breathing exercises are the basis of many relaxation techniques. The ability to regulate breathing and to relax are important mechanisms of self-regulation and allows you to achieve a wide range of tasks of the program of correction of emotional state. These include regulation of the functional state, regulation of various mental states, mobilization of physiological and mental reserves of a person, emotional preparation for certain activities, reducing the emotional stress. Self-regulation is not only the ability to perform certain complexes of exercise, but also a conscious attitude to the internal processes, the ability to control feelings and to form adequate actions. Depth of relaxation depends on breathing. Thus, in childbirth, a woman can reduce pain by managing the depth and rhythm of breathing.

Special visualization technique can be used in conjunction with relaxation. It shapes the skills of conscious management of imagery. The power of imagination creates positive images that contribute to the desired effect on the physical level. Depending on the purpose of the technique, imaging may be therapeutic, psychotherapeutic or healing.

There are effective practices and examples of specially developed models, such as Resource Art therapy of N. Kovalenko ${ }^{13}$. The comprehensive approach is important for the implementation of psycho-correction.

Psychological counseling. Perinatal mental health refers to a woman's mental health during pregnancy and the postpartum period. The vast majority of research on perinatal mental health examines non-psychotic common perinatal mental disorders (CPMDs), and the majority of studies focus specifically on anxiety and depression. Inadequate screening and referral systems often result in women with perinatal mental health issues going undiagnosed and untreated.

Perinatal Counseling of expectant families is performed by a professional consultant or psychotherapist. This work requires special training under programs of perinatal psychology and psychotherapy.

Therefore, a prenatal family counseling covers:

- psychoprevention of emotional crises in young families;

- psychocorrection of internal family relations and balancing of family bonds;

13 Kovalenko N.P. (2000). Perinatal psychology. Saint Petersburg: Publishing house «Juventa» [in Russian]. 
- preparations to parenthood and labor; psychocorrection of pathologising emotions in pregnancy (anxiety, fear, offense);

- help growing into mother's and father's role and teaching of parental functions;

- resource therapy to family members who cracked down under the psychological and emotional pressure of child expecting and delivering (N. Kovalenko ${ }^{14}$, 2000).

Health surveys indicate growing demand for psychological counseling during pregnancy and postpartum period. Perinatal psychologist is a specialist providing assistance at the stage of planning pregnancy, providing support and education of women or family during pregnancy and after birth. In Ukraine perinatal psychology specialists are practitioners with basic medical, pedagogical or psychological education who took additional perinatal psychology courses. There are no professional courses available on the basis of higher education institutions. Perinatal courses for specialists can be find as author's trainings developed by practitioners. Courses are held on the basis of non-governmental organizations (associations of conscious parents or centers of psychology).

\section{The Course "Methods and Techniques of Perinatal Psychological Care"}

It is important to support the expansion of a knowledge base in Perinatal Psychology trough training, research, and sharing examples of effective practice. The results of conducted scientific research and practical work were summarized and formed the basis of the course "Methods and techniques of perinatal psychological care". The course consists of two modules and contains the following topics: psychology of conception, pregnancy and childbirth, features of perinatal development of the child, basics of perinatal care, perinatal psychological support and parental education. Within the course the theoretical and methodological foundations of perinatal psychology are examined, the methods of psychological diagnostics in the context of perinatal subjects are determined, the forms and methods of psychological work with the family in the period of planning, expectation and early development of the child are studied, practical methods and techniques of perinatal psychological assistance are worked out.

The purpose of teaching the course "Methods and techniques of perinatal psychological care" is to ensure the students' personal readiness for future

14 Kovalenko N. Perinatal Psychology and Psychotherapy Experience of the Russian Association of Perinatal Psychology and Medicine Int. J. Prenatal and Perinatal Psychology and Medicine. Vol. 20 (2008) No. 3/4, pp. 138-147 
professional activity by acquiring students with the theoretical and practical basics of perinatal care.

The main tasks of the course are:

- to introduce the theoretical and methodological foundations of perinatal psychology as a new science;

- to define methods of diagnostics and practical methods of work of perinatal psychology;

- to acquaint with the methods of diagnostic the early child development,

- to introduce with the forms and methods of psychological work with the family during the period of planning, expectation and early postnatal period;

- to master the basic practical methods and techniques of perinatal psychological support.

According to the requirements of the educational and professional program students must achieve the following learning outcomes (competences):

- ability to conduct a diagnostic psychological examination and apply its results;

- to provide counseling to families during the planning, expectation and after birth of a child;

- to know the peculiarities of psychological diagnostics of conditions that require correction by means of psychological and therapeutic help.

Table 1

Teaching Modules of the Course "Methods and Techniques of Perinatal Psychological Care"

\begin{tabular}{|l|l|}
\hline \multicolumn{1}{|c|}{ Module } & \multicolumn{1}{c|}{ The content } \\
\hline Module 1 & Fundamentals of perinatal psychology. \\
\hline Module 2 & Psychology of conception, pregnancy and childbirth \\
\hline Module 3 & Features of perinatal child development. \\
\hline Module 4 & The system of perinatal care in Ukraine \\
\hline Module 5 & Basics of psychological perinatal support \\
\hline Module 6 & $\begin{array}{l}\text { Psychological support of the family with a child } \\
\text { (postnatal period) }\end{array}$ \\
\hline Module 7 & Final Evaluation \\
\hline
\end{tabular}

Section 1. Theoretical and methodological foundations of perinatal psychology.

Topic 1. Fundamentals of perinatal psychology. Perinatal psychology as a new field of research and practice, history of development. Methodological 
principles of perinatal psychology. Subject and tasks of perinatal psychology. Applied aspects of perinatal support: optimization of early child development through psychological preparation for paternity and correction of parent-child relationship; prenatal development and education; psychotherapy and psychocorrection of disorders of early child development.

Topic 2. Psychology of conception, pregnancy and childbirth. Stages of formation of family system, style of family interaction. Content and regularities of formation of paternity. Methods of assessment of family processes. Conception at different stages of the family life cycle. Unplanned pregnancy. Psychology and physiology of pregnancy. Prenatal stress and its effects. Pregnancy styles. Psychological component of gestational dominance. Diagnostic work with pregnant women and families. Psychological tasks of preparation for childbirth and becoming a parent.

Topic 3. Features of perinatal child development. The impact of early ontogeny on personality development. The driving forces, mechanisms and conditions of child development (the perinatal period). Influence of pregnancy on the health of baby. Stages of prenatal development. Prenatal Self. Basics of mother-child contact: norm, disorders and remedies. Birth experience. Society and baby before birth. Basic aspects of early child development: physical, perceptual, cognitive, emotional, social development.

Section 2. Applied aspects of perinatal psychological care.

Topic 4. The system of perinatal care. Content and specifics of maternity care in different countries (Ukraine, Europe, South America). Maternity perinatal care (maternity homes, antenatal clinics, perinatal centers, conscious paternity associations). Characteristics of three-level perinatal care system in Ukraine. Perinatal care legislation. Main directions of work of perinatal psychologists.

Topic 5. Basics of perinatal care. Conscious parenting: ways of formation. Prenatal development and upbringing. Diagnostic work with pregnant women and families. Features of psychological counseling of pregnant women at the stage of reproductive choice. Work with perinatal losses. Systemic family therapy and psychological counseling with the family at the stage of expectation and birth. Art- therapy and body-oriented techniques of work with expectant parents. Basic needs of women in childbirth. Support in childbirth.

Topic 6. Psychological support of the family with a child (postnatal period). Optimization of early child development through psychological preparation for parenthood and correction of parental relationships. Postpartum depression: manifestations, causes, psychological help. Prevention perinatal mental health issues. Attachment theory and education. Parent education.

The main outcomes of the educational course. After studying the course, the student should be able: 
- to apply basic diagnostic techniques and psycho-correction methods working with pregnant women and families;

- to develop programs for individual and group activities working with pregnant women and families;

- to provide counseling to families during the planning, expectation and after birth of a child;

- to apply methods of perinatal psychological support.

The course has been taught for the master students of psychology (specialization "Psychotherapy and counseling") at Zaporizhzhia National University, Ukraine.

It should be noted that interactive education is applied to fulfill the outcomes of the course. The interactive lectures activate the problem-seeking content of educational activities, promoting the activation of students' independent work.

Various discussion methods (debate, guided conversation, scale of thoughts) are necessary to create the conditions for organized discussion of problematic issues, to motivate the participants to determine his or her attitude to the issue, to promote tolerant communication.

The imitation technologies include situational exercises, role games, case studies, psychological training. The use of imitation technologies is based on the modeling of professional situations. The goal is to develop professional thinking in solving a problem based on the analysis of a specific situation. It also helps to master teamwork skills.

The organization of educational activities of students using the tools of interactive learning is a key component in professional training. Interactive approach is a prerequisite for the formation of important professional qualities, such as reflection, creativity, ability for active collaboration and interaction. Interactive learning provides the result of professional training to be personally oriented for all participants of the educational process.

\section{CONCLUSIONS}

Perinatal issues are interesting and relevant. Promotion of perinatal health spans multiple disciplines and sectors, and therefore requires coordination and collaboration among national agencies, institutions and professionals.

Perinatal psychology is a new scientific field that emerged in conjunction of different sciences The scientific findings of perinatal psychology has far reaching consequences for the human race.

Perinatal care includes having access to a range of good-quality information and services: family-planning counseling, information, education, communication and services, including access to safe and effective 
contraceptive methods; education and services for prenatal care, safe delivery and post-natal care, especially breast-feeding and infant and women's health care, parental education. Perinatal period can be defined as the start determining the potential of human health.

Health surveys indicate growing demand for psychological assistance during pregnancy and postpartum period. The role of perinatal psychological support is crucial. Perinatal support is a system of joint professional activity, aimed at creating favorable social and psychological conditions for women and families during pregnancy, childbirth and also during the first year(s) after birth. The object of perinatal psychological support is the psycho-emotional state of (future) parent(s), the subject is the socio-psychological conditions for successful pregnancy and the formation of readiness for parenthood.

Parenting has the primary influence on children's development. There is a lack of programs to prepare and educate future parents. The psychological component of perinatal care includes a complex of measures aimed at providing psychological support to women and families at the stage of planning pregnancy, during pregnancy and after birth of a child. If perinatal mental health problems are identified and treated effectively, serious and often life-changing human and economic costs can be avoided.

The main areas of perinatal practices are: perinatal education (training of future parents, preparation for childbirth and parenthood, forming of conscious parenting), individual and family counseling, psychological support of mother and families.

Practical aspects of perinatal psychological care include but are not limited to:

- psychological assistance to the family (prenatal period, pregnancy, childbirth, postpartum period)

- diagnostics of readiness for motherhood and paternity;

- Psychological preparation for paternity (prenatal development and education), correction of parental relationships

- Psycho-correction of mother's psycho-emotional state during pregnancy, childbirth and in the postpartum period;

- psychotherapy and psycho-correction of disorders of early personality development.

Effective perinatal support during pregnancy and the early postpartum together with facilitating transition to parenthood has the potential to promote more healthy individuals, families, communities and societies. Psychologically sensitive, multidisciplinary, and culturally appropriate care is a priority in providing the effective perinatal care. 


\section{SUMMARY}

The article has dealt with the practical aspects of perinatal psychological care. The issue of implementation of basic evidence-based principles of perinatal care have been raised. The main areas of perinatal practices were analyzed: psychological diagnostic, psychological prevention and education (training of future parents, preparation for childbirth and parenthood, forming of conscious parenting), psychological correction and psychotherapy, individual and family counseling. Practical methods of perinatal psychology were described. Perinatal psychological support was defined a complex of measures aimed at providing psychological assistance to women and families at the stage of planning pregnancy, during pregnancy, birth and postpartum period. The results of conducted scientific research and practical work were summarized and formed the basis of the educational course "Methods and techniques of perinatal psychological care" revised in the article.

\section{REFERENCES}

1. The British Psychological Society. URL: https://www.bps.org.uk/

2. Chalmers, B., Mangiaterra, V., \& Porter, R. (2001). WHO Principles of Perinatal Care: The Essential Antenatal, Perinatal, and Postpartum Care Course. Birth, 28(3), 202-207.

3. The International Society for Pre-and Perinatal Psychology and Medicine. URL: https://isppm.de/

4. Odent M. (2013). Childbirth and the Future of Homo sapiens. Pinter \& Martin. London.

5. Guba N., Mosol N., Syusyuka V. (2019) Promoting Prenatal Health And Positive Birth Outcomes: Perinatal Psychological Support. Problem space of modern society: philosophical-communicative and pedagogical interpretations: collective monograph. Warsaw: BMT Erida Sp. z o.o. 2019. P. $166-180$.

6. Craig G., Baucum D. (2002) Human Development (9th Edition). Upper Saddle River, NJ : Prentice-Hall.

7. Chamberlain D. (1998). The Mind of Your Newborn Baby. North Atlantic Books.

8. Grof S. (1985) Beyond the Brain: Birth, Death and Transcendence in Psychotherapy. State University of New York Press.

9. Verny Thomas R. (1981).The Secret Life of the Unborn Child, (with Kelly). Summit Books, USA and Collins, Canada.

10. Dobryakov I.V. (2015). Perinatal psychology. Saint Petersburg: Piter [in Russian]. 
11. Filippova G.G. The method of drawing tests in psychological work with pregnant women. [in Russian]. Available from: http://childpsy.ru/lib/ articles/id/9574.php (Accessed: 20 December 2019).

12. National Institute of Child Health and Human Development. URL: https://www.nichd.nih.gov

13. Kovalenko N.P. (2000) Perinatal psychology. Saint Petersburg: Publishing house "Juventa" [in Russian].

14. Kovalenko N. (2008) Perinatal Psychology and Psychotherapy Experience of the Russian Association of Perinatal Psychology and Medicine Int. J. Prenatal and Perinatal Psychology and Medicine Vol. 20 (2008) No. 3/4, pp. $138-147$.

Information about the author:

Mosol N. O.,

Ph.D. in Psychology, Associate Professor,

Docent of Psychology Department, Zaporizhzhia National University 66, Zhukovskoho str., Zaporizhzhia, 69600, Ukraine 